\footnotetext{
JURNAL CEMERLANG: Pengabdian pada Masyarakat

P-ISSN 2654-4741 / E-ISSN 2655-7894

Vol. 2, No. 2, Juni 2020, 133 - 147

DOI: https://doi.org/10.31540/jpm.v2i2.908

PENERBIT: LP4MK STKIP PGRI LUBUKLINGGAU
}

\title{
PELATIHAN PEMANFAATAN SUMBER PUSTAKA DALAM MENUNJANG PENULISAN MAKALAH ILMIAH BAGI GURU SMK NEGERI 10 TANGERANG
}

\author{
Merry Lapasau, Mamik Suendarti, Lestarini Sumotenodjo \\ Universitas Indraprasta PGRI, Indonesia \\ Email: lapasaumerry@yahoo.com, suendarti@gmail.com, renelestari@gmail.com
}

\begin{abstract}
ABSTRAK
Pemanfaatan sumber pustaka daring dalam menunjang penulisan makalah ilmiah di kalangan guru SMKN 10 Tangerang masih merupakan hal yang kurang dipraktekkan. Berdasarkan hasil kuesioner awal diketahui bahwa para guru SMKN 10 belum banyak mengetahui bagaimana cara mencari atau memanfaatkan sumber pustaka elektronik dalam menunjang penulisan makalah ilmiah. Oleh karena itu, tim abdimas UNINDRA melakukan kegiatan pengabdian kepada masyarakat yang bertujuan untuk meningkatkan pengetahuan dan kemampuan guru-guru dalam mencari, memanfaatkan dan menyusun sumber pustaka dalam basis data daring secara sistematis sehingga mereka mampu menerapkan pengetahuan tersebut dalam menulis makalah ilmiah untuk diterbitkan dalam jurnal. Metode yang digunakan dalam kegiatan tersebut adalah ceramah dan tanya jawab. Dapat disimpulkan bahwa kegiatan PKM yang dilaksanakan oleh tim dosen dari universitas Indraprasta PGRI Jakarta di SMKN 10 Tangerang tersebut dapat diterima dan diikuti dengan baik oleh guru-guru di sekolah tersebut. Untuk kegiatan lebih lanjut diperlukan adanya pelatihan lanjutan berupa penulisan artikel ilmiah secara tematik sehingga guru-guru mampu secara mandiri menulis makalah untuk jurnal nasional dengan pemanfaatan basis data sebagai sumber pustaka secara maksimal.
\end{abstract}

ABSTRACT

Utilization of digital library resources in supporting the writing of scientific papers among teachers of SMK 10 Tangerang is still not practiced. Based on the results of the initial questionnaire, it was found out that the vocational high school teachers did not know much about how to find or utilize electronic library resources to support writing scientific papers. Therefore, this community service activity by UNINDRA aims to improve the knowledge and abilities of teachers in searching, utilizing, and compiling library resources in online databases systematically so that they are able to apply this knowledge in writing scientific papers for publication in journals. The method used is the lecture and question and answer method. It can be concluded that the PKM activities in SMKN 10 Tangerang in providing guidance on writing scientific papers, especially regarding the use of library resources, can be well received and followed by the teachers. For further activities, further complete trainings are needed in the form of writing scientific articles so that teachers are able to write papers for national journals independently with maximum utilization of library resources. 


\section{JURNAL CEMERLANG: Pengabdian pada Masyarakat \\ P-ISSN 2654-4741 / E-ISSN 2655-7894 \\ Vol. 2, No. 2, Juni 2020, 133 - 147 \\ DOI: https://doi.org/10.31540/jpm.v2i2.908 \\ PENERBIT: LP4MK STKIP PGRI LUBUKLINGGAU \\ KEYWORDS \\ Pemanfaatan Sumber Pustaka, Makalah Ilmiah \\ Utilization Of Library Sources, Scientific Work \\ ARTICLE HISTORY \\ Received 05 April 2020 \\ Revised 07 May 2020 \\ Accepted 11 May 2020}

CORRESPONDENCE Merry Lapasau @ lapasaumerry@yahoo.com

\section{PENDAHULUAN}

Penulisan makalah ilmiah untuk diterbitkan dalam jurnal ilmiah bereputasi nasional saat ini masih belum merupakan praktek yang diminati para guru sekolah di Indonesia, termasuk juga di SMKN 10 Tangerang. Saat ini, salah satu yang menjadi kendala bagi guru untuk dapat naik ke golongan IV B adalah adanya persyaratan menulis makalah ilmiah. Menurut Prayitno et.al (2001), makalah ilmiah adalah suatu makalah yang memuat dan mengkaji suatu masalah tertentu dengan menggunakan kaidah-kaidah keilmuan. Kaidah keilmuan yang dimaksud adalah penggunaan metode ilmiah dalam membahas permasalahan, menyajikan kajian dengan menggunakan bahasa baku dan tata tulis ilmiah, serta menggunakan prinsip-prinsip keilmuan yakni bersifat objektif, logis, empiris, sistematis, lugas, jelas dan konsisten.

Dalam pelaksanaan tugasnya, seorang guru dituntut untuk mengembangkan keprofesian secara berkelanjutan yaitu dengan mengembangkan kompetensinya yang dilaksanakan sesuai dengan kebutuhan, bertahap, berkelanjutan untuk meningkatkan profesionalitasnya. Pengembangan keprofesian berkelanjutan, meliputi: pengembangan diri, publikasi ilmiah, dan makalah inovatif. Peraturan Menteri Pendayagunaan Aparatur Negara Dan Reformasi Birokrasi RI Nomor 16 Tahun 2009 mengatur bahwa ruang lingkup kegiatan publikasi ilmiah meliputi publikasi ilmiah atas hasil penelitian atau gagasan inovatif pada bidang pendidikan formal dan publikasi buku teks pelajaran, buku pengayaan, dan pedoman guru (Herowati et al, 2018). 


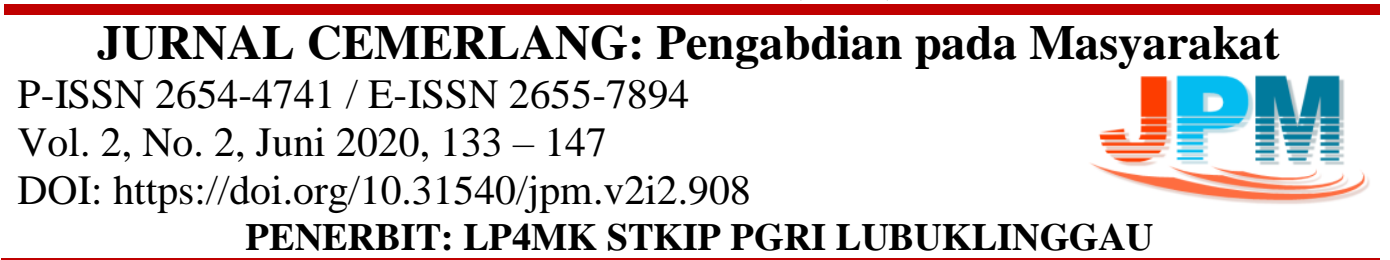

Menurut Dalman (2012), suatu karya tulis dapat dikategorikan sebagai makalah ilmiah jika memiliki karakterisitik tertentu dan dapat dikaji minimal dari 4 aspek, yaitu:

a. Struktur.

Struktur kajian karya ilmiah sangat ketat, biasanya terdiri dari bagian awal, bagian inti, dan bagian penutup. Bagian awal merupakan pengantar ke bagian inti, sedangkan inti merupakan sajian gagasan pokok yang ingin disampaikan.

b. Komponen dan substansi

Komponen karya ilmiah bervariasi sesuai dengan jenisnya, namun semua karya ilmiah mengandung pendahuluan, bagian inti, penutup, dan daftar pustaka. Artikel ilmiah yang dimuat dalam jurnal mempersyaratkan adanya abstrak.

c. Sikap penulis. Sikap penulis dalam karya ilmiah adalah objektif, yang disampaikan dengan menggunakan kata atau gaya bahasa impersonal.

d. Penggunaan bahasa. Bahasa yang digunakan dalam karya ilmiah adalah bahasa baku yang tercermin dari pilihan kata atau istilah, dan kalimatkalimat yang efektif dengan struktur yang baku.

Di SMKN 10, para guru merasa kesulitan untuk menulis makalah ilmiah disebabkan beberapa alasan antara lain kurangnya pengetahuan bagaimana cara membuat makalah ilmiah yang bermutu yang dapat diterbitkan di jurnal serta minimnya bimbingan yang diberikan kepada mereka. Hal tersebut sejalan dengan pendapat Jaedun yang menyatakan bawa fakta di lapangan menunjukkan masih kurangnya jumlah guru yang memiliki kemampuan, kemauan, dan kebiasaan menulis. (Jaedun, 2011). Penelitian relevan yang dilakukan Noorjanah (2014) memberikan beberapa informasi mendasar yang berkaitan tentang kesulitan yang biasa dihadapi guru dalam penulisan makalah ilmiah. Menurut Noorjanah, (2014) kesulitan para guru tersebut dapat dibagi dalam dua kategori, yaitu: kesulitan 


\section{JURNAL CEMERLANG: Pengabdian pada Masyarakat \\ P-ISSN 2654-4741 / E-ISSN 2655-7894 \\ Vol. 2, No. 2, Juni 2020, $133-147$ \\ DOI: https://doi.org/10.31540/jpm.v2i2.908 \\ PENERBIT: LP4MK STKIP PGRI LUBUKLINGGAU}

internal dan kesulitan eksternal. Kesulitan internal meliputi: motivasi diri atau minat, waktu, teknik penulisan, pengumpulan data di lapangan, dan kurang melek teknologi. Kesulitan ekternal berupa: ketersediaan buku referensi, maraknya jasa penulisan makalah tulis, kurang berfungsinya MGMP, dan kurangnya sosialisasi dari lembaga atau sekolah. SMKN 10 Tangerang menjadi tempat pelatihan karena para guru yang bekerja di sekolah tersebut belum banyak yang pernah menulis makalah ilmiah selain untuk kebutuhan kuliah seperti skripsi atau tesis dan sampai saat diadakan kegiatan pengabdian masyarakat yang dilakukan tim abdimas dari Universitas Indraprasta PGRI, pihak sekolah belum pernah menyelenggarakan kegiatan yang serupa.

Kegiatan pengabdian masyarakat ini bertujuan untuk memberikan pelatihan tentang bagaimana cara pemanfaatan basis data sebagai sumber pustaka dalam penulisan makalah ilmiah, baik sumber pustaka yang bersumber dari pemerintah maupun umum. Kegiatan pengabdian masyarakat ini membatasi pencarian sumber pustaka dalam bentuk e-resources sehingga guru-guru yang mendapat pelatihan dapat dengan mudah mengakses sumber pustaka tersebut. Basis data sumber pustaka tersebut adalah: DOAJ, PROQUEST, SCIENCE DIRECT, DAN PORTAL GARUDA. DOAJ merupakan singkatan dari directory of open access journals, yaitu basis data yang menyediakan akses gratis ke jurnal dan artikel ilmiah yang telah melalui proses review. DOAJ mengindex sebanyak 14,141 judul jurnal dan 4,524,411 artikel (per 30 desember 2019). Jurnal dan artikel tersebut dipublikasikan oleh 130 negara.

Beberapa jurnal dan artikel yang diindex oleh DOAJ juga terindex pada penyedia pustaka berbayar seperti Scopus dan Web of Science. ProQuest merupakan salah satu fulltext database dan AI (Abstract and Index) yang dilanggan oleh Kemenristekdikti. Jenis koleksi yang terdapat dalam Proquest terdiri dari e-journal, e-book, video dan audio, basis data tesis dan disertasi serta beberapa jenis publikasi lain yang dapat dipergunakan untuk menunjang penelitian dan penulisan makalah ilmiah. Bidang ilmu yang dilanggan saat ini 


\section{JURNAL CEMERLANG: Pengabdian pada Masyarakat \\ P-ISSN 2654-4741 / E-ISSN 2655-7894 \\ Vol. 2, No. 2, Juni 2020, 133 - 147 \\ DOI: https://doi.org/10.31540/jpm.v2i2.908 \\ PENERBIT: LP4MK STKIP PGRI LUBUKLINGGAU}

adalah bidang ilmu sosiologi dan biologi. Science direct merupakan basis data yang dikeluarkan oleh Elsevier. Basis data ini menyediakan referensi dari metadata sampai dokumen lengkap yang berasal dari publikasi jurnal, konferensi dan buku. Basis data ini mencakup semua bidang ilmu. Portal Garuda (Garda rujukan digital) merupakan portal pencarian terpadu publikasi ilmiah dan mengindeks artikel dari seluruh peguruan tinggi dan institusi yang diterbitkan di Indonesia.

Masalah utama yang dihadapi guru-guru di kalangan SMKN 10 Tangerang adalah kurangnya pengetahuan mereka tentang bagaimana mencari sumber pustaka yang bereputasi dan dapat diakses secara bebas tanpa harus membayar. Tanpa memiliki akses bebas ke sumber pustaka yang kredibel, tentunya penulisan makalah ilmiah tidak dapat dilakukan dengan leluasa. Hal-hal mendasar seperti itu juga dapat menyebabkan rendahnya motivasi untuk menulis makalah ilmiah, ditambah lagi dengan minimnya pelatihan atau bimbingan yang mereka dapati dari sekolah.

Oleh karena itu, tim abdimas Universitas Indraprasta PGRI membatasi pelaksanaan PKM dengan kegiatan pemanfaatan sumber pustaka dalam basis data untuk menunjang efektifitas guru dalam menulis makalah ilmiah. Tujuan dari kegiatan PKM ini adalah untuk meningkatkan motivasi guru dalam menulis makalah ilmiah, memperluas pengetahuan guru tentang akses-akses ke berbagai basis data sumber pustaka yang bisa menjadi sumber inspirasi dalam menetapkan tema makalah ilmiah yang akan ditulis serta untuk menambah referensi sehingga para guru dapat menghasilkan makalah ilmiah yang bermutu.

\section{METODE}

Pelaksanaan pengabdian ini terdiri dari dua kegiatan dengan langkahlangkah sebagai berikut: Wawancara dengan kepala sekolah dan penyebaran kuesioner dan kegiatan inti yaitu pengabdian masyarakat. Uraian kegiatan tersebut sebagai berikut: 


\section{JURNAL CEMERLANG: Pengabdian pada Masyarakat \\ P-ISSN 2654-4741 / E-ISSN 2655-7894 \\ Vol. 2, No. 2, Juni 2020, $133-147$ \\ DOI: https://doi.org/10.31540/jpm.v2i2.908 \\ PENERBIT: LP4MK STKIP PGRI LUBUKLINGGAU}

\section{Wawancara dan Kuesioner}

Pada kegiatan pertama, dilakukan penyebaran kuesioner untuk guru dan kepala sekolah SMKN 10 Tangerang untuk mengetahui bagaimana minat dan motivasi serta kemampuan dan pengalaman guru-guru di SMKN 10 mengenai penulisan makalah ilmiah. Tim abdimas juga ingin mengetahui bagaimana usahausaha para guru SMKN 10 Tangerang dalam meningkatkan kemampuan menulis makalah ilmiah. Hasil kuesioner yang diperoleh digunakan sebagai acuan pada pelaksanaan pengabdian masyarakat.

\section{Pengabdian Masyarakat}

Kegiatan pengabdian masyarakat ini merupakan pelatihan terhadap guruguru SMKN 10 yang berlokasi di Jl. Rorotan, RT.001/ RW.002, Babakan Asem, Kecamatan Teluknaga, Tangerang, Banten 1551. Kegiatan inti berupa pelatihan bagaimana cara memanfaatkan sumber pustaka dalam penulisan makalah ilmiah dengan alat bantu proyektor dan laptop pada tanggal 11 November 2019 yang berlangsung selama kurang lebih tiga jam. Para guru diberikan penjelasan secara rinci tentang cara mendapatkan sumber pustaka dan bagaimana cara pemanfaatannya sebagai penunjang referensi dalam penulisan makalah ilmiah mereka. Sumber pustaka pemerintah: http://e-resources.perpusnas.go.id, portal Garuda (http://garuda.ristekdikti.go.id/). Panduan bisa dilihat di laman internet kemenristekdikti_Tahun_2017.pdf. Basis data sebagai sumber pustaka umum bisa didapat contohnya dari: http://doaj.org, Proquest (http://search. proquest.com/), sci-hub (mis. http://sci-hub.tw), http://aisel.aisnet.org, http://researchgate.net.

Pelatihan diakhiri dengan sesi diskusi dengan memberikan kesempatan kepada para guru untuk bertanya dengan lebih terinci mengenai materi pelatihan tersebut.

\section{HASIL dan PEMBAHASAN}

Struktur materi PKM adalah sebagai berikut: 


\section{JURNAL CEMERLANG: Pengabdian pada Masyarakat \\ P-ISSN 2654-4741 / E-ISSN 2655-7894 \\ Vol. 2, No. 2, Juni 2020, $133-147$ \\ DOI: https://doi.org/10.31540/jpm.v2i2.908 \\ PENERBIT: LP4MK STKIP PGRI LUBUKLINGGAU}

Pemahaman pentingnya memanfaatkan basis data sebagai sumber pustaka dalam menulis makalah ilmiah.

Sumber pustaka mencakupi bahasan aktual terhadap suatu masalah yang tengah dikaji seorang penulis yang sekaligus merupakan sebuah basis bagi penulis untuk 'menjamin' pernyataan dan argumentasinya. Dengan pemanfaatan sumber pustaka yang aktual, seorang penulis dapat mengetahui perkembangan penelitian terbaru di bidangnya sehingga ia dapat mengangkat nilai novelty tulisannya. Makalah ilmiah sejatinya dapat membuktikan kebenaran semua pernyataan, teori, hipotesis atau hasil. Namun, kita sebagai peneliti tidak mungkin dan tidak perlu untuk memberikan semua bukti sendiri karena hal ini akan berarti kita harus mendapatkan semua dasar ilmiah yang digunakan dengan melakukan interpretasi, uji hipotesis ulang, pengukuran sendiri dan lain-lain. Sumber pustaka memang memberikan semua bukti ilmiah yang kita perlukan, namun kita juga harus tahu dimana menemukan dan bagaimana memanfaatkan mereka. Oleh karena itu, pencarian sumber pustaka yang komprehensif melalui basis data sangatlah penting. Pemanfaatan sumber pustaka bukan hanya tentang transfer pengetahuan yang ada semata, tetapi merupakan pemikiran kritis dan 'perdebatan' logis ilmiah dengan latar belakang pertanyaan penelitian kita sendiri.

Dengan memasuki bidang yang kita kaji secara mendalam, kita mampu mengembangkan ide-ide baru hingga nantinya kita dapat mengajukan pertanyaan lebih lanjut. Hanya mereka yang telah memahami topik dengan luas dan mendalam serta mengenal keadaan penelitian saat ini akan mampu menyajikan pertanyaan penelitian mereka dan memberikan solusinya secara mandiri untuk pembaca berpengalaman yang juga merupakan ahli di bidangnya.

\section{Pemahaman tentang makalah ilmiah secara garis besar.}

Pada bagian ini, para guru peserta pelatihan diberikan contoh-contoh artikel ilmiah di bidang pendidikan dari jurnal yang dapat diakses dengan bebas. Hal ini dilakukan untuk memberikan gambaran kepada peserta pelatihan secara global bagaimana dan tema apa saja yang layak masuk dalam jurnal ilmiah nasional. Selain itu, kegiatan ini diharapkan juga dapat memberikan ide kepada para guru 


\footnotetext{
JURNAL CEMERLANG: Pengabdian pada Masyarakat

P-ISSN 2654-4741 / E-ISSN 2655-7894

Vol. 2, No. 2, Juni 2020, 133 - 147

DOI: https://doi.org/10.31540/jpm.v2i2.908

PENERBIT: LP4MK STKIP PGRI LUBUKLINGGAU
}

untuk memulai menulis tentang tema-tema yang sedang aktual.

\section{Pemahaman tentang bagian yang harus ada dalam suatu makalah ilmiah} secara garis besar.

Pada bagian ini peserta diberi pemahaman tentang bagaimana struktur sebuah makalah ilmiah dibangun, yaitu umumnya terdiri dari:

- Judul

- Baris Kepemilikan

- Abstrak

- Pendahuluan

- Metode

- Hasil dan Pembahasan

- Kesimpulan

- Daftar Pustaka

Pembahasan utama: Pemanfaatan sumber pustaka dalam basis data untuk menunjang penulisan makalah ilmiah

Menurut Rettig (2017) sumber pustaka yang digunakan dalam makalah ilmiah dibagi menjadi dua jenis, yaitu sumber pustaka primer dan sumber pustaka sekunder.

Sumber pustaka primer adalah sumber pustaka yang menjadi bahan utama atau objek penelitian. Sumber ini biasanya berupa karya sastra atau fiksi, non fiksi atau sumber lainnya seperti iklan, film, artikel di surat kabar, buku pelajaran sekolah dan lain-lain yang menjadi objek analisis atau interpretasi.

Sumber pustaka sekunder atau sumber pustaka penunjang penelitian merupakan sumber rujukan ilmiah yang digunakan untuk membantu memecahkan masalah yang dikaji atau menjadi pertanyaan penelitian yang bersumber pada sumber pustaka primer. Cakupan sumber pustaka sekunder dapat merujuk pada sumber pustaka primer, tetapi tidak harus. Jika suatu makalah ilmiah meneliti atau menganalisis suatu sumber pustaka primer (misalnya suatu karya sastra), maka kedua jenis sumber pustaka ditulis dalam judul terpisah dalam daftar pustaka atau rujukan. Namun jika sebuah penelitian tidak meneliti atau menganalisis sebuah sumber pustaka primer, maka kedua jenis sumber pustaka tersebut tidak perlu ditulis terpisah dalam daftar rujukan. 


\section{JURNAL CEMERLANG: Pengabdian pada Masyarakat P-ISSN 2654-4741 / E-ISSN 2655-7894 \\ Vol. 2, No. 2, Juni 2020, $133-147$ \\ DOI: https://doi.org/10.31540/jpm.v2i2.908 \\ PENERBIT: LP4MK STKIP PGRI LUBUKLINGGAU}

Pemanfatan sumber pustaka daring atau elektronik sebagai akses yang menghemat pencarian sumber pustaka aktual dapat berupa: a) artikel jurnal ilmiah, b) penerbitan hasil konferensi atau prosiding, c) buku, d) tesis, e) disertasi, f) laporan penelitian, g) laporan statistik.

Banyak perpustakaan sudah memiliki kemungkinan untuk merekam makalah ilmiah secara digital. Dengan cara ini, berbagai macam basis data telah dibuat yang memudahkan kita mencari sumber pustaka. Pencarian modern saat ini biasanya sudah berbasis daring dan membutuhkan pencarian melalui basis data.

\section{Pencarian sistematis}

Pencarian sistematis mencakup pencarian kata kunci spesifik yang berasal dari topik pilihan tertentu dalam katalog basis data. Jurnal yang paling penting (tahun-tahun terakhir), buku-buku dan media cetak lainnya ditampilkan secara teratur sehingga memberikan gambaran yang baik tentang suatu topik. Pencarian sistematis sangat cocok untuk pencarian bertarget untuk mendapatkan informasi tertentu dengan menggunakan kata kunci.

\section{Pengenalan terminologi operator pencarian dalam basis data sumber pustaka digital}

- DAN (AND) berarti kedua istilah (semua, jika ada lebih dari dua istilah) akan dimasukkan dalam hasil pencarian. Tambahan kata "DAN" memperluas pencarian dengan aspek lain dan membatasi jumlah hasil pencarian yang sesuai.

- ATAU (OR) berarti bahwa setidaknya satu dari istilah yang dicari termasuk dalam hasil pencarian yang ditampilkan. Tambahan kata "ATAU" memperluas pencarian dengan sinonim lain dan (biasanya) meningkatkan jumlah hasil pencarian.

- TIDAK (NOT) mengecualikan istilah berikutnya untuk ditampilkan. Namun, pencarian dengan kata tersebut harus digunakan dengan hati-hati, karena hasil pencarian yang sangat berguna juga bisa hilang jika misalnya istilah yang dikecualikan tersebut ditulis didalam anak kalimat yang tidak penting dalam konteks keseluruhan. 


\section{JURNAL CEMERLANG: Pengabdian pada Masyarakat \\ P-ISSN 2654-4741 / E-ISSN 2655-7894 \\ Vol. 2, No. 2, Juni 2020, $133-147$ \\ DOI: https://doi.org/10.31540/jpm.v2i2.908 \\ PENERBIT: LP4MK STKIP PGRI LUBUKLINGGAU}

- Tanda kurung (...) menautkan beberapa istilah dalam pencarian dengan operator yang berbeda. Selain itu, pencarian dengan karakter karakter "*" dan "?" juga terbukti menjadi alat yang sangat berguna dalam pencarian sumber data digital.

\section{Persyaratan umum}

Tidak semua sumber rujukan cocok dan diizinkan untuk digunakan dalam makalah ilmiah. Ada kriteria penilaian yang jelas yang harus kita perhatikan mengingat banyaknya keragaman sumber. Daftar pustaka sebagai rekaman sumber pustaka seyogyanya hanya memuat rujukan sumber yang memang digunakan (yaitu direferensikan) untuk penulisan makalah ilmiah. Kriteria formal, yaitu bahwa sumber pustaka dapat diverifikasi, menjadi kriteria utama dalam pemilihan sumber pustaka. Kriteria kedua adalah bahwa kita harus mencantumkan asal sumber pustaka yanng kita gunakan dengan jelas sehingga pembaca dapat memverifikasinya sendiri apabila terdapat hal yang kurang jelas atau pembaca ingn membaca lebih detail. Selanjutnya, tanggal penerbitan juga harus disertakan untuk informasi aktualitas sumber pustaka. Tidak kalah penting tentunya kita harus mencantumkan nama pengarang sumber tersebut atau nama editornya sebagai penanggungjawab.

Berikut tampilan dalam laman basis data digital:

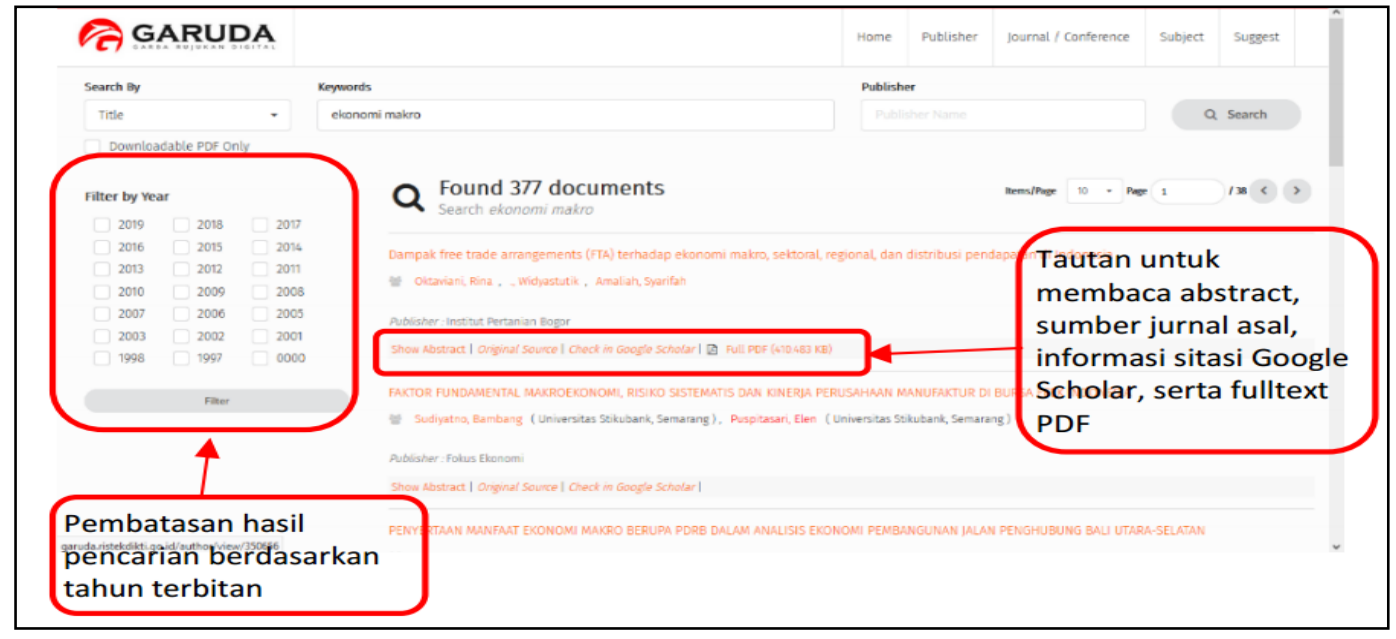

Gambar1. Tampilan laman awal GARUDA

https://ojs.stkippgri-lubuklinggau.ac.id/index.php/JPM 


\section{JURNAL CEMERLANG: Pengabdian pada Masyarakat \\ P-ISSN 2654-4741 / E-ISSN 2655-7894 \\ Vol. 2, No. 2, Juni 2020, 133 - 147 \\ DOI: https://doi.org/10.31540/jpm.v2i2.908 \\ PENERBIT: LP4MK STKIP PGRI LUBUKLINGGAU}

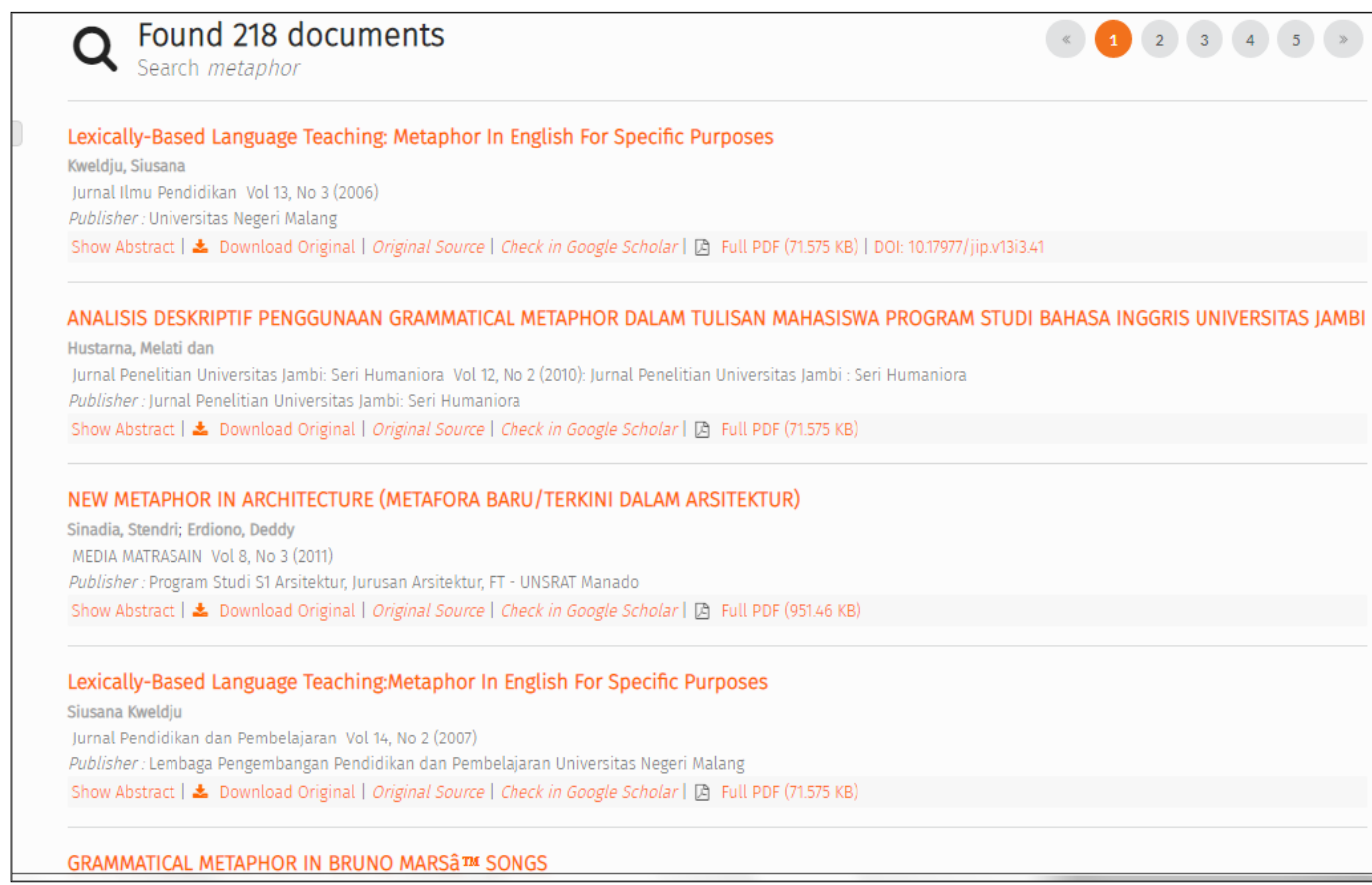

Gambar 2. Laman pencarian dokumen

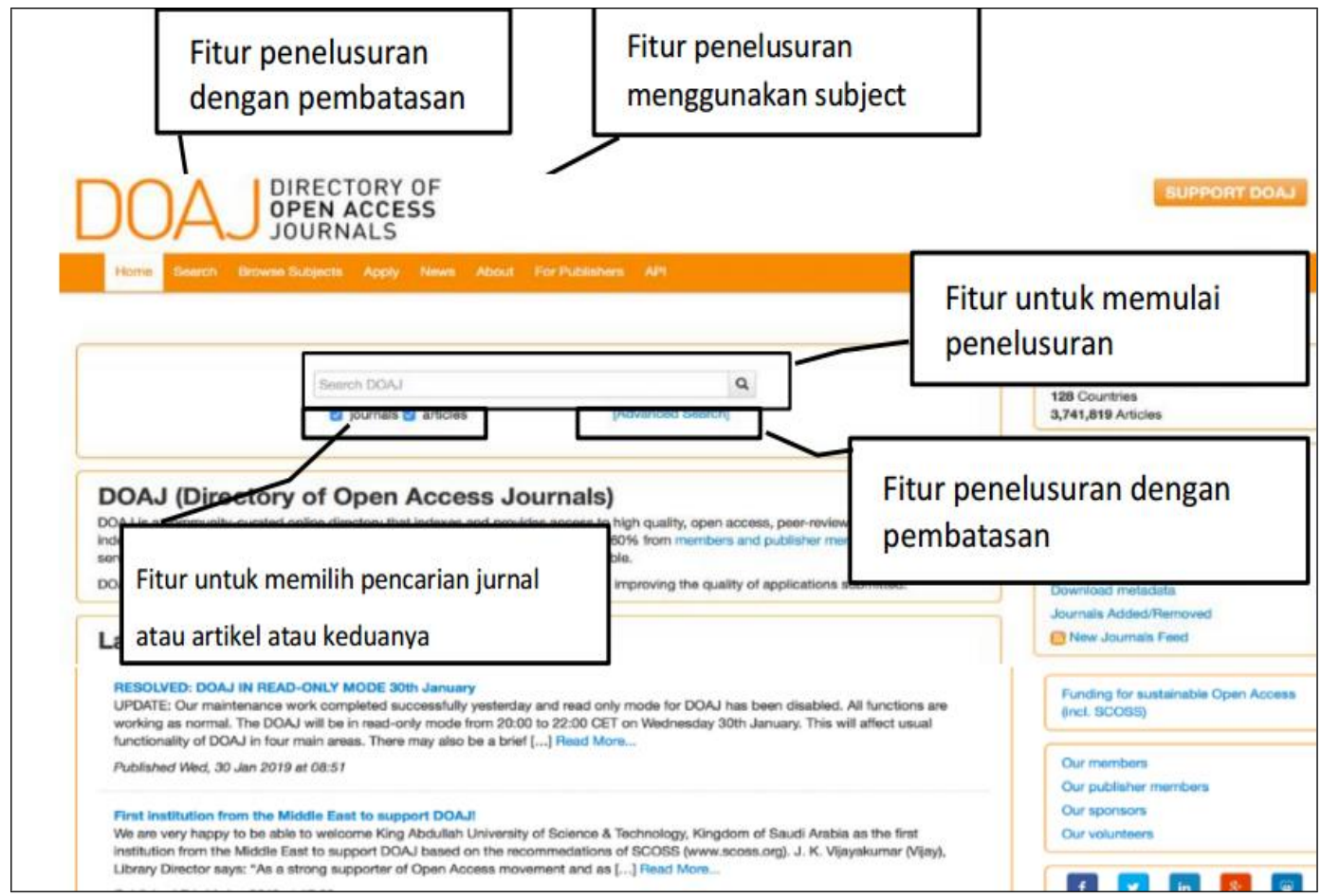

Gambar 3. Tampilan laman awal DOAJ

https://ojs.stkippgri-lubuklinggau.ac.id/index.php/JPM 


\section{JURNAL CEMERLANG: Pengabdian pada Masyarakat}

P-ISSN 2654-4741 / E-ISSN 2655-7894

Vol. 2, No. 2, Juni 2020, 133 - 147

DOI: https://doi.org/10.31540/jpm.v2i2.908

PENERBIT: LP4MK STKIP PGRI LUBUKLINGGAU

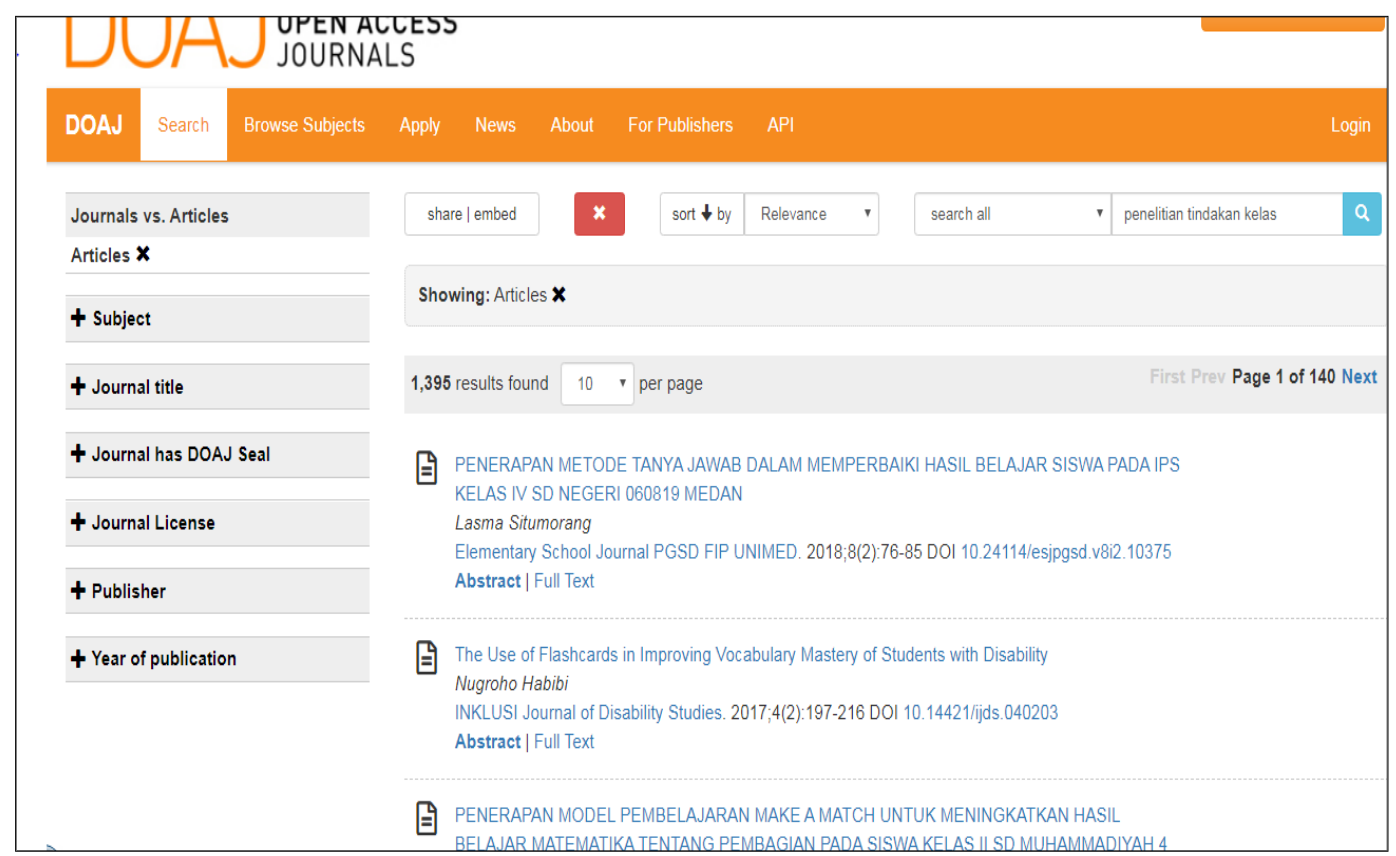

Gambar 4. Tampilan laman dokumen doaj

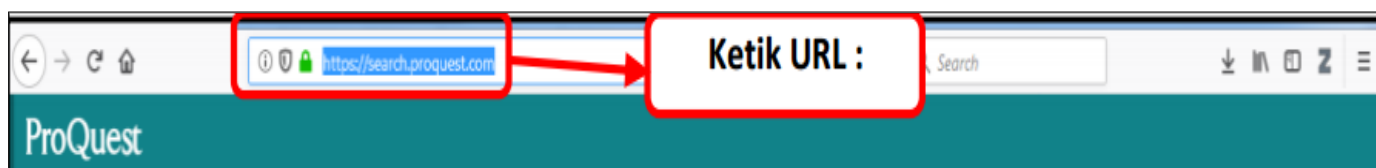

Trying to access content on ProQuest?

Other access options

Use one of the options below to see if you have access

Jika akses

Connect through your library or institution

melalui

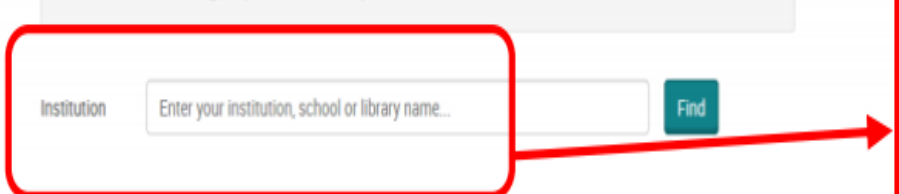

lingkungan

institusi maka

akan langsung

Or log in with your ProQuest account

masuk ke

tampilan

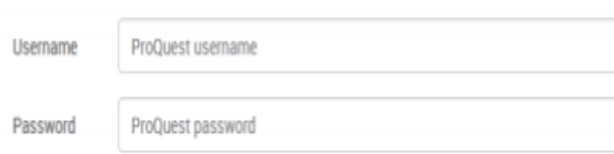

Gambar 5. Tampilan laman awal Proquest 

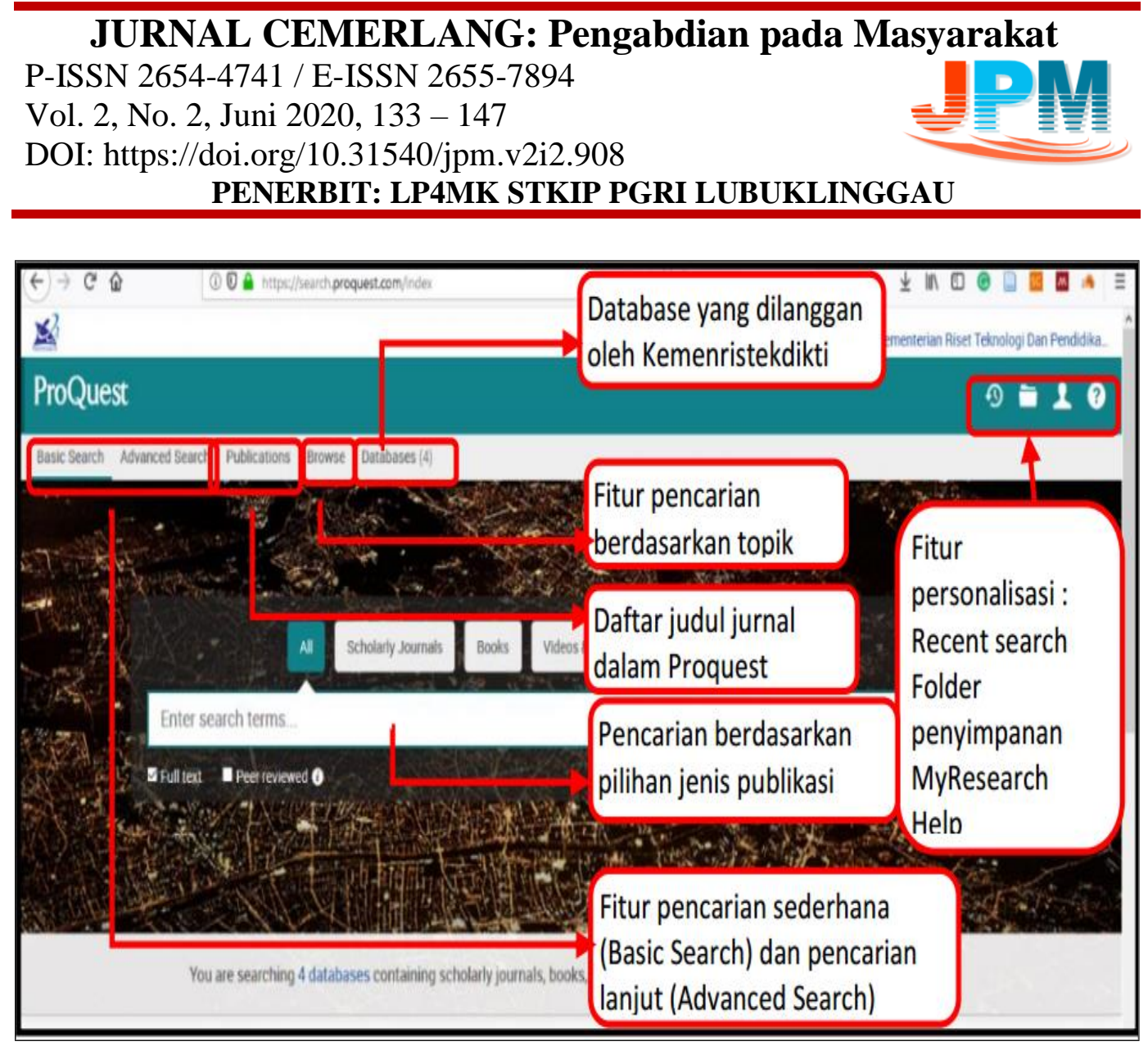

Gambar 6. Tampilan laman pencarian Proquest

2. Tautan ke sumber jurnal asal

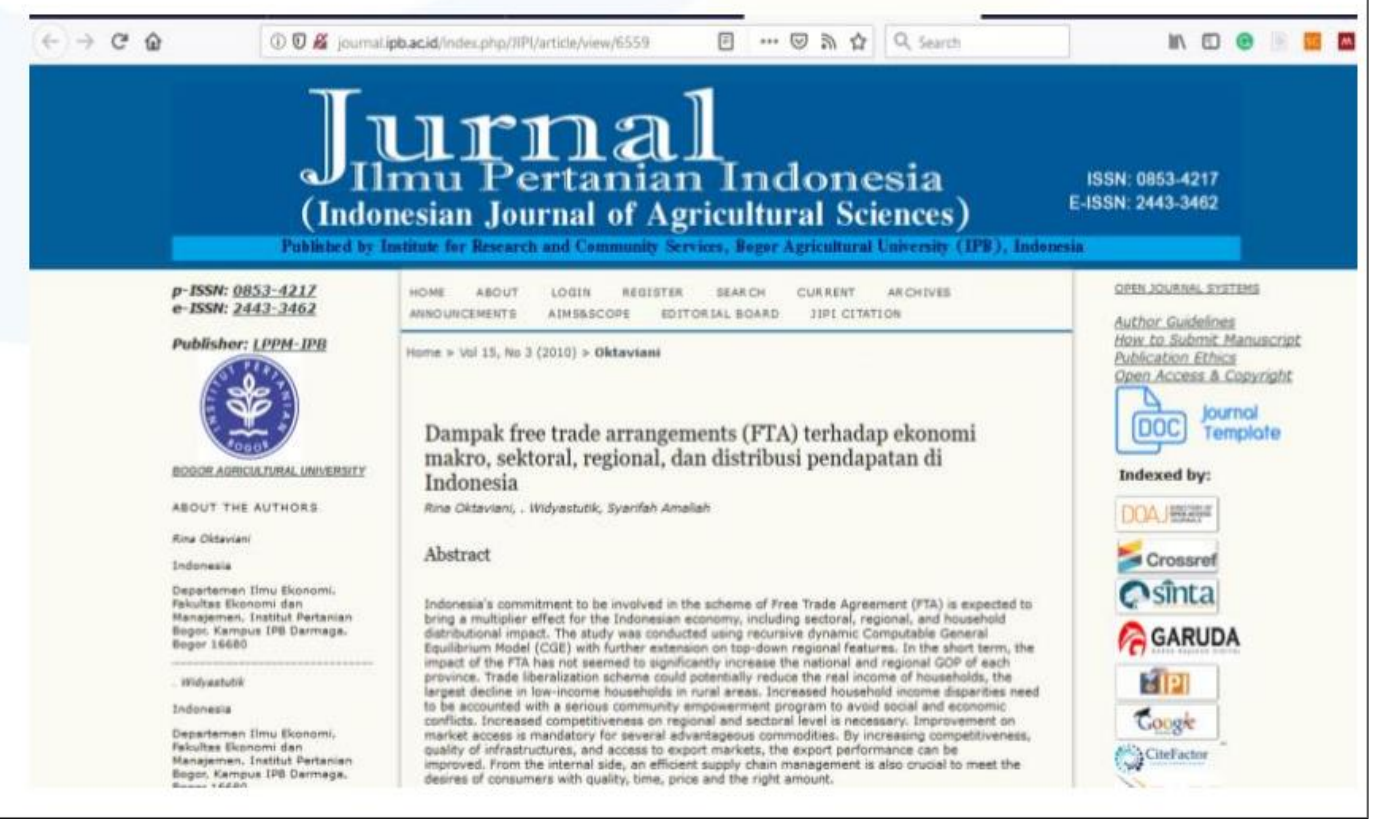

Gambar 7. Tautan ke sumber jurnal

https://ojs.stkippgri-lubuklinggau.ac.id/index.php/JPM 
JURNAL CEMERLANG: Pengabdian pada Masyarakat

P-ISSN 2654-4741 / E-ISSN 2655-7894

Vol. 2, No. 2, Juni 2020, $133-147$

DOI: https://doi.org/10.31540/jpm.v2i2.908

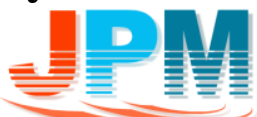

PENERBIT: LP4MK STKIP PGRI LUBUKLINGGAU

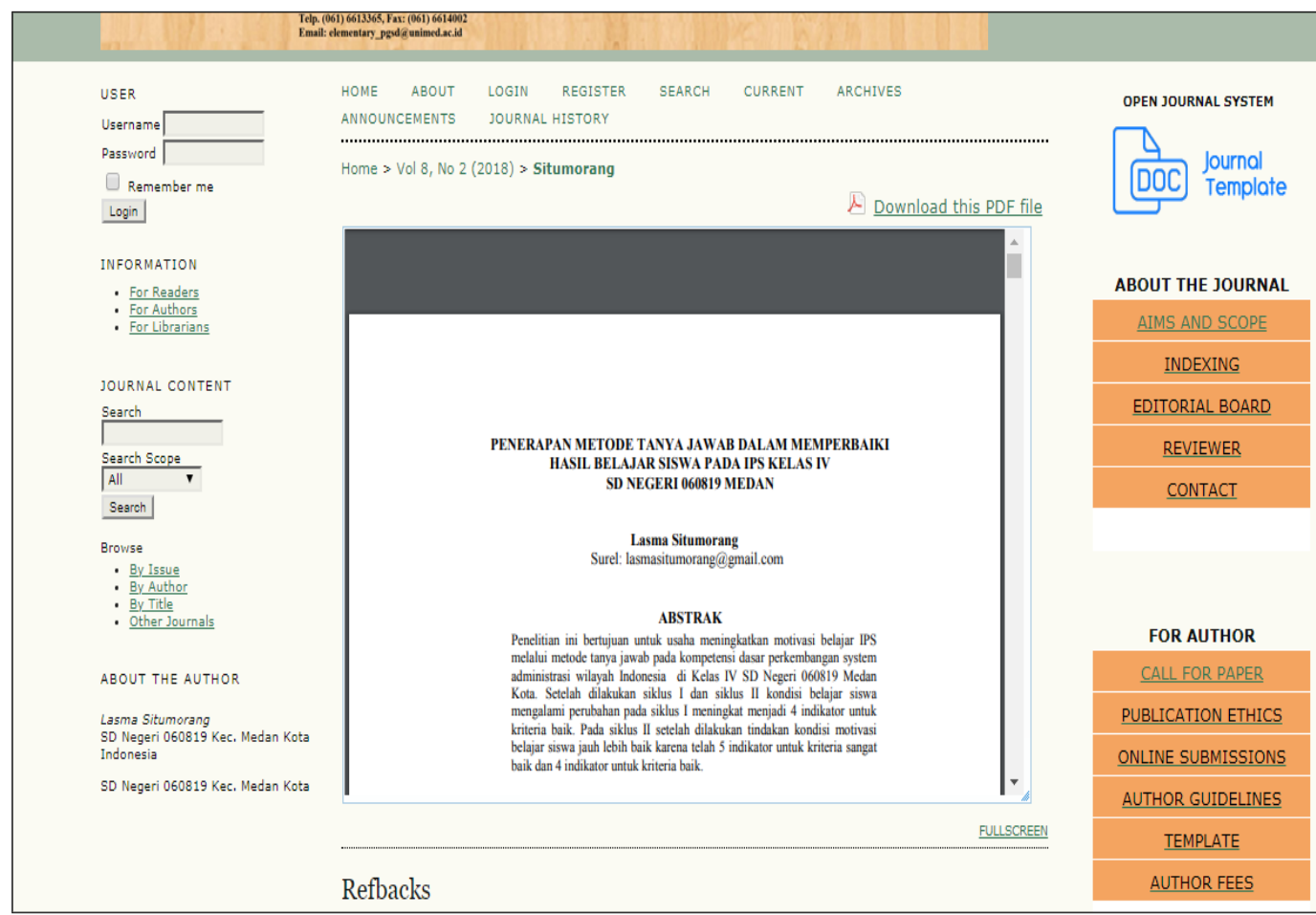

Gambar 8. Tampilan jurnal yang dapat diunduh

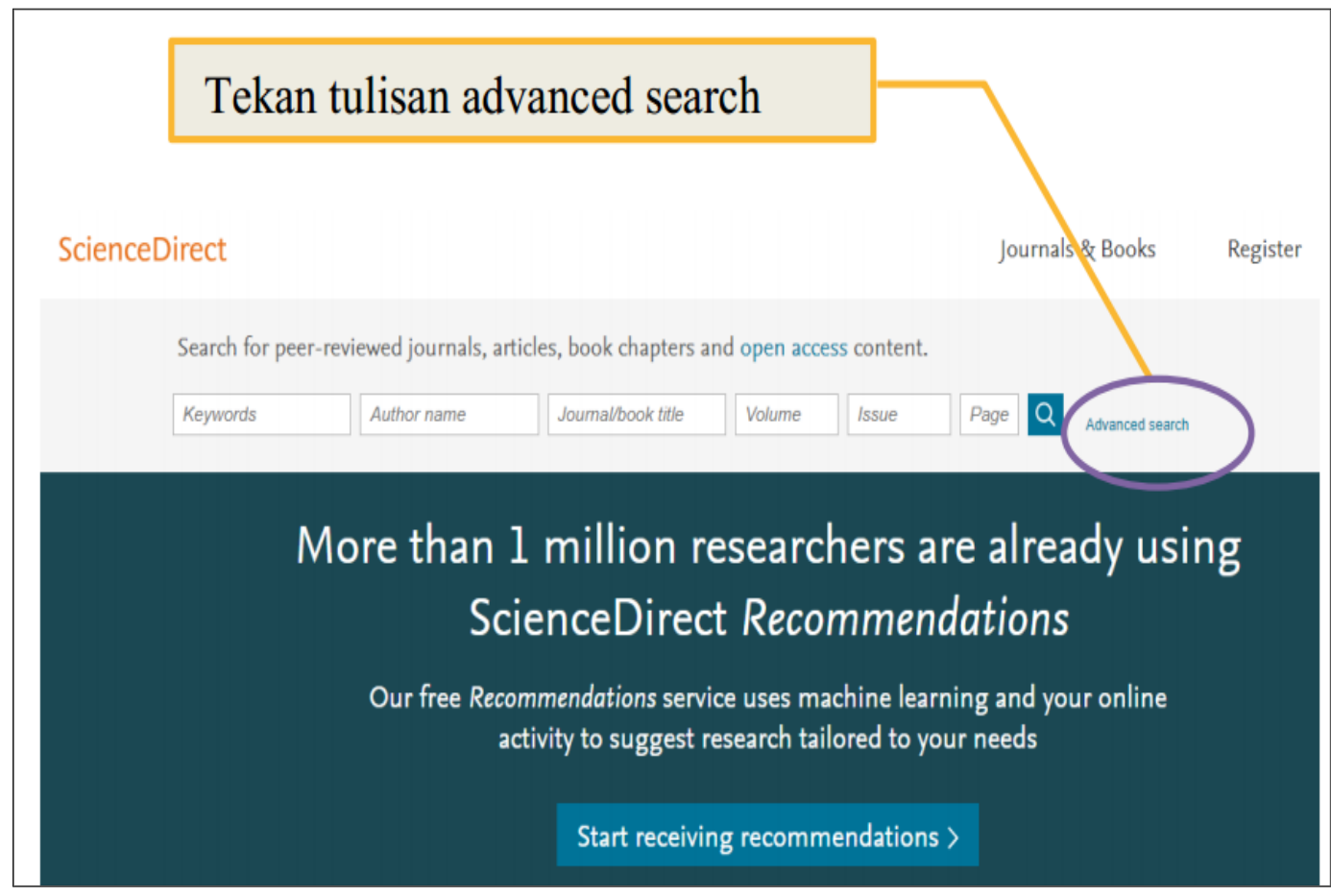

Gambar 9. Tampilan awal Science direct 

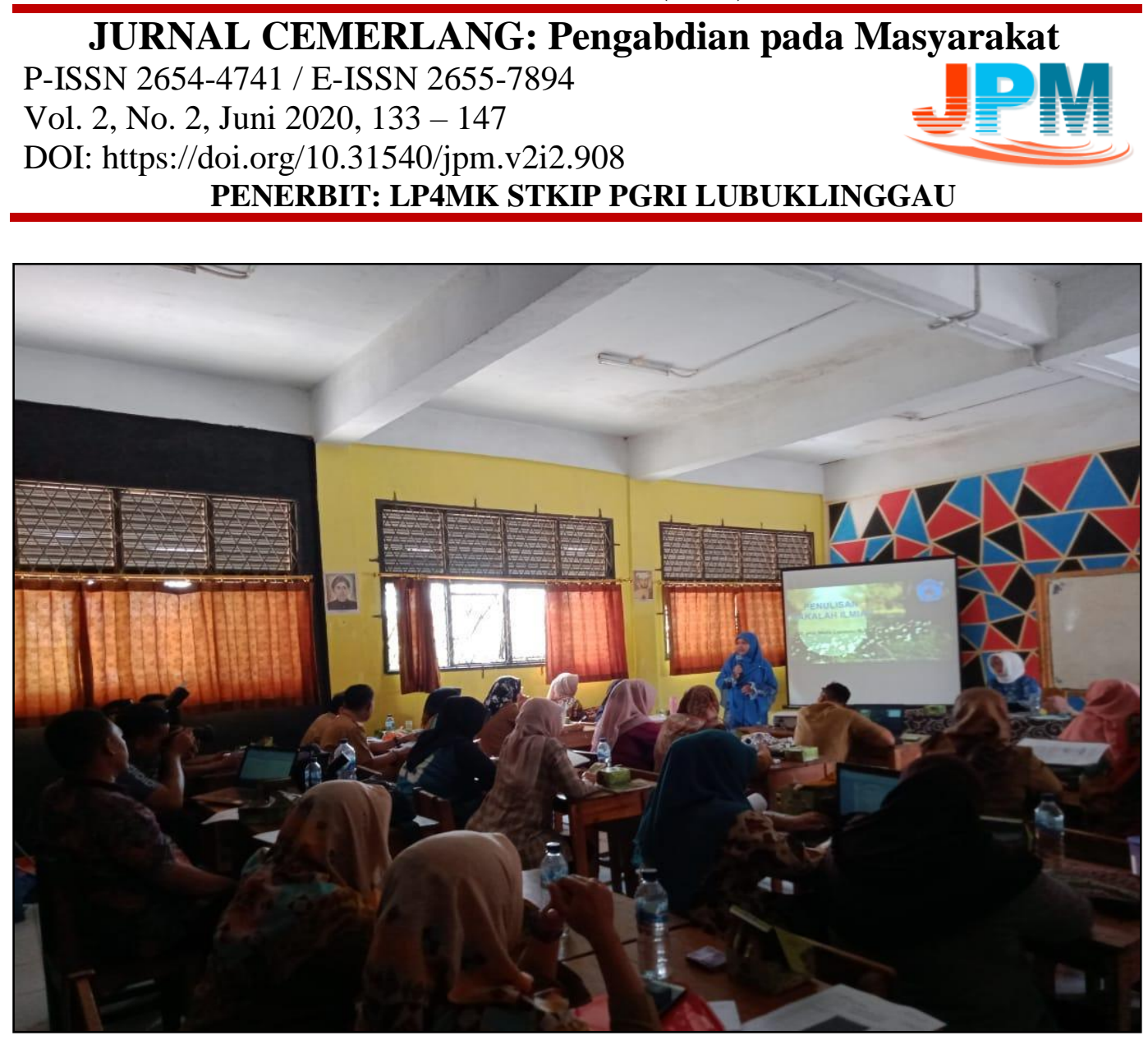

Gambar 10. Pelaksanaan Abdimas

Selama kegiatan berlangsung, tim abdimas tidak menemui kendala yang berarti. Pihak sekolah SMKN 10 Tangerang sebagai mitra juga menunjukkan antusiasme selama kegiatan yang dapat diamati melalui pertanyaan-pertanyaan yang datang dari para guru sebagai peserta pelatihan.

\section{SIMPULAN}

Dapat disimpulkan bahwa kegiatan PKM yang dilaksanakan oleh tim dosen dari universitas Indraprasta PGRI Jakarta di SMKN 10 Tangerang tersebut dapat diterima dan diikuti dengan baik oleh guru-guru di sekolah tersebut. Untuk kegiatan lebih lanjut diperlukan adanya pelatihan lanjutan berupa penulisan artikel ilmiah secara tematik sehingga guru-guru mampu secara mandiri menulis makalah untuk jurnal nasional dengan pemanfaatan basis data sebagai sumber pustaka secara maksimal. 


\footnotetext{
JURNAL CEMERLANG: Pengabdian pada Masyarakat

P-ISSN 2654-4741 / E-ISSN 2655-7894

Vol. 2, No. 2, Juni 2020, 133 - 147

DOI: https://doi.org/10.31540/jpm.v2i2.908

PENERBIT: LP4MK STKIP PGRI LUBUKLINGGAU
}

\section{UCAPAN TERIMA KASIH}

Kami menyampaikan ucapan terima kasih kepada Lembaga Penelitian dan Pengabdian kepada Masyarakat Universitas Indraprasta PGRI Jakarta atas bimbingan dan arahan yang menyangkut kegiatan PKM dan SMKN 10 Tangerang selaku tuan rumah yang menyediakan tempat kegiatan PKM. Ucapan terima kasih juga kami sampaikan kepada mitra bestari jurnal Cemerlang yang telah membantu dalam menerbitkan makalah ini.

\section{DAFTAR PUSTAKA}

Baker, Allan. (2018). Essay Writing Explained: How to Write an Essay. Bookboon. ISBN 9788740305715

Dalman. (2012). Menulis Karya Ilmiah. Jakarta: Raja Grafindo Persada

Herowati, R; Widodo,G; Supriyadi, Sunarti, Keswara, Y; Purnamasari, N. (2018). Pelatihan Penulisan Makalah Ilmiah bagi Guru SMA untuk Meningkatkan Kualitas Guru. J-ABDIPAMAS (Jurnal Pengabdian Kepada Masyarakat) Vol. 2 No.1, 85-90

Jaedun, A. (2011). Pengembangan Profesionalisme Guru Melalui Penulisan Karya Tulis Ilmiah. Disampaikan Pada Kegiatan Seminar Karya Tulis Ilmiah dan Penelitian Tindakan Kelas di SMK Negeri 1 Sedayu, Bantul.

Kementerian Riset, Teknologi, dan Pendidikan Tinggi. (2019). Pemanfaatan Sumber Pustaka dan Perangkat Penunjang Publikasi Ilmiah. Jakarta: Direktorat Jenderal Penguatan Riset dan Pengembangan Kementerian Riset, Teknologi, dan Pendidikan Tinggi Bekerjasama dengan Pusat Penelitian Informatika, Lembaga Ilmu Pengetahuan Indonesia (LIPI).

Lilies Noorjanah. (2014). Pengembangan Profesionalisme Guru Melalui Penulisan Makalah Tulis Ilmiah Bagi Guru Profesional di SMA Negeri 1 Kauman Kabupaten Tulungagung. Jurnal Humanity, ISSN 0216-8995. 97-114

Martin Kache, Marcus Römer, Michael Müller, Sebastian Günther. (2015). Leitfaden Literaturreserche. Technische Universität Dresden. Fakultät Verkehrswissenschaften „Friedrich List““ Institut für Bahnfahrzeuge und Bahntechnik 


\section{JURNAL CEMERLANG: Pengabdian pada Masyarakat}

P-ISSN 2654-4741 / E-ISSN 2655-7894

Vol. 2, No. 2, Juni 2020, 133 - 147

DOI: https://doi.org/10.31540/jpm.v2i2.908

PENERBIT: LP4MK STKIP PGRI LUBUKLINGGAU

Prayitno, H D. dkk. (2001). Pembudayaan Penulisan Makalah Ilmiah. Surakarta: Muhammadiyah University Press.

Rettig, H. (2017). Wissenschaftliche Arbeiten schreiben. Stuttgart: SpringerVerlag http://eprints.ums.ac.id/46114/1/NASKAH\%20PUBLIKASI.pdf

https://www.i17.in.tum.de/fileadmin/w00btn/www/teaching/Reader_DE.pdf

Schmidt, H. (2011). Erfolgreich wissenschafliche Arbeiten schreiben. Ventus Publishing ApS. ISBN 978-87-7681-942-2 